\title{
New Achievements, Recognition and a Farewell
}

\author{
Domingo M. Braile1, MD, PhD; Camila Sáfadi Alves Gonçalves²; Paulo Roberto B. Evora³ , MD, PhD;
}

Significant changes are being made in the Brazilian Journal of Cardiovascular Surgery - BJCVS, beginning in May 2019: the ahead of print. The ahead of print mode allows publishers to submit articles that reviewers have already approved directly to the PubMed and SciELO databases, already with the digital object identifier (DOI). In the future, these articles will compose an issue of BJCVS to be published. The ahead of print mode has some advantages: one is to allow research papers to be published continuously and more quickly, so that the results can impact and be recognized before in the academic community. Thus, there is no need to wait for an issue to be composed to be published. The other advantage is that the articles indexed more quickly in the databases are available for citation, thus helping to recognize the article and the researcher. BJCVS articles are now available in PubMed and SciELO.

The BJCVS also wants to pay tribute to Dr. Rosângela Monteiro, one of the most important collaborators of the journal, who since 1998 provided editorial advice to the BJCVS in publishing, revision and standardization. She also collaborated in important projects for the development of BJCVS, such as journal indexing in the most important national and international databases. In addition, together with Prof. Fabio B. Jatene and Prof. Domingo M. Braile, helped implement the peer review system, created the journal's website, and implemented the publication management system, which allowed BJCVS to internationalize. Her academic background is also extensive: she has a bachelor's degree in Biology from Universidade Presbiteriana Mackenzie, a master's degree in Anatomy from the School of Veterinary Medicine and Zootechnics at Universidade de São Paulo and a PhD in Sciences from the Thoracic and Cardiovascular Surgery Program of the Medical School at Universidade de São Paulo. Currently, she is

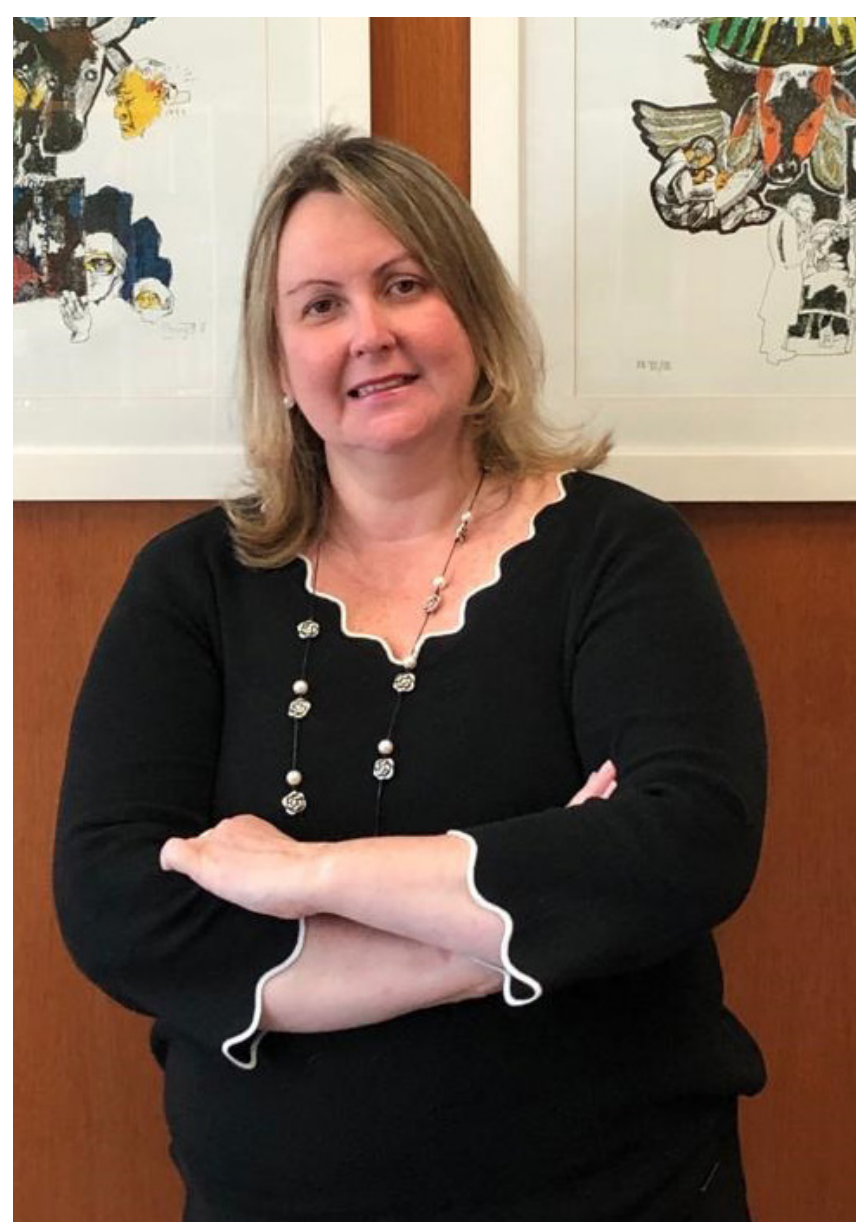

Tribute from BJCVS to Dr. Rosângela Monteiro. 
chief biologist at the Thoracic Surgery Department of the Heart Institute (InCor) of the Hospital das Clínicas, Medical School at University of São Paulo, an institution that she has been linked since 1992. Dr. Monteiro stated that" When I was reviewing an BJCVS article, I was studying."

BJCVS wishes success to Dr. Rosângela in her career!

\section{Articles in this Issue}

This issue of BJCVS presents a blind peer-reviewed selection of 18 papers that were selected by order of acceptance: 12 original papers, 1 review article, 1 special article, 3 selected case reports and 1 educational. In response to our editorial efforts, three Letters to the Editor have been included in this issue.

\section{Acknowledgment}

We would like to express our gratitude to all the BJCVS authors, reviewers, and associate editors who keep hard working to raise the level of this publication. Special acknowledgment to Prof. Noedir Stolf for the additional editorial.

\section{Domingo M. Braile}

(iD) https://orcid.org/0000-0001-7704-2258

'Editor-in-Chief - BJCVS

Faculdade de Medicina de São José do Rio Preto (FAMERP), São José do Rio Preto, SP, Brazil and Universidade de Campinas (UNICAMP), Campinas, SP, Brazil.

\section{Camila Sáfadi Alves Gonçalves}

(iD) https://orcid.org/0000-0003-0611-7229

25ociedade Brasileira de Cirurgia Cardiovascular, São Paulo, SP, Brazil.

\section{Paulo Roberto B. Evora}

(iD) https://orcid.org/0000-0001-9631-946X

${ }^{3}$ Editor-in-Chief Interim - BJCVS

Faculdade de Medicina de Ribeirão Preto da Universidade de São Paulo (FMRP-USP), Ribeirão Preto, SP, Brazil.

\section{REFERENCES}

1. Guia para publicação avançada de artigos Ahead of Print (AOP) no SciELO [Internet]. São Paulo: SciELO; 2019 [cited 2019 Jun 6]. 5 p. Available from: https://wp.scielo.org/wp-content/uploads/guia_AOP.pdf 